\title{
THE EFFECT OF BREAK FEEDING OF PASTURES
}

By A. V. ALLO, Instructor in Agriculture, Department of Agriculture, Tauranga.

In his presidential address our chairman stressed the necessity for increasing our exports of foodstuffs to Britain. The purpose of this paper is. to indicate one; method by which our dairy production can be increased by the better utilisation of our pastures.

I think we are all agreed on the fact that we are by no means getting the maximum production from our dairy pastures. It is a noticeable fact that many farmers will pay high prices for the best grass, seed available, and will topdress their pastures liberally, but do not get the full benefit from the grass they grow. For years we have been told that the most efficient utilisation of our dairy pastures is obtained when they are grazed'off at a height of 8 to 9 inches. At this stage we have both quality and bulk of feed, and our aim should be to have our dairy stock actually grazing on this class of pasture for the longest possible period during the milking season. We have sought to achieve this by cutting down the size of our paddocks and by rotationally grazing our herds. Although this system of pasture management was a great improvement on the system of extensive grazing with large fields, it is not sufficient in itself to permit of the maximum production from our dairy pastures, as it is too inflexible to compensate for varying rates of pasture growth at different periods of the year.

We all know what happens in a dairying district during the milking season. In the early spring the herd can cope with the new growth in a paddock. Then, as the flush commences, we see the feed getting away from them. If the farmer tries to keep them on the area until the paddock is cleaned up, they become restless after a couple of days and want a change of pasture, even though there may be ample feed still on the area. If they do not get this change they show their resentment by a decline in production, so that the farmer is more or less compelled to move his herd 
on to a fresh paddock before the old one is properly grazed down. The next. time this paddock is grazed in the rotation, instead of the grass being of a uniform. height, it varies from 4 to 8in. to quite rank growth. This latter is neglected by the cows, which concentrate on the shorter, sweeter feed. This process continues throughout the season, and, with good growing conditions during summer and autumn, we see many dairy farms covered with rough feed-feed that should have been utilised by the cows to produce butterfat if only it had been grazed in its productive stage. On many dairy farms this loss of production must be a considerable percentage of the total farm production.

How can this wastage of productive feed; be overcome ? The most practicable method of obtaining full pasture utilisation is to vary the area of grass available to the herd to suit the feed position by using the electric fence and feeding off the grass in breaks. This practice is already being adopted by most dairy farmers in the utilisation of their autumn-saved pasture, and my purpose is to show that this system of pasture utilisation could be continued with profit throughout the full dairying season.

Few dairy farmers today would dream of turning their cows loose on to a paddock of autumn-saved pasture. They realise that this practice results in too great a waste of good feed. Instead, they use the electric fence to ration off this grass in breaks, varying the size of the break according to the time of the year and the amount of grass available. This break feeding is usually continued until the spring flush of pasture growth comes away, when the electric fence unit is put away in the shed until the following spring, and the normal practice of rotational grazing, using full-sized paddocks, is adopted.

It is claimed that if dairy farmers would only continue to use the electric fence to feed off their grass in breaks right through the season, or at least as long as the feed position makes it practicable, there would be a. marked improvement in the efficiency of our pasture utilisation and consequently an increase in our production.

This system of "break grazing," as it is called, is already being carried on by a number of dairy farmers in the North Island who have proved that it is both practicable and profitable. They have obtained some marked production increases, as will be shown later,

78 . 
and, in addition, there is strong evidence to indicate that this system of grazing can be of considerable value in-reducing the incidence of bloat on those farms susceptible to this trouble.

The first essential in the operation of this s'ystem is to have a satisfactory electric fence unit, preferably in a portable, water-tight container, so that is can be used in the paddock being grazed off and shifted daily. It has been found that having the unit in the cowshed and reticulating the farm from this focal point is not so satisfactory in practice, owing to the amount of wiring involved and the greater risks of these wires "shorting."

Standards should be strong, light, and easily pushed into the ground, and several satisfactory types are on the market. Many types of insulator are available, manufactured from porcelain or rubber, while many farmers use home-made ones of claw-rubbers or old inflations. Although there is a loss of current through rubber insulators, in practice they prove to be very satisfactory. Heavy-gauge plain wire or barbed wire should not be used to fence off the breaks, owing to difficulties of handling. Fine-gauge wire is quite satisfactory, as is fine telephone wire. Reels on which this wire can be wound can be purchased quite cheaply and any farmer who uses the electric fence is recommended to get one.

In the grazing management, it is essential that dairy cows always have access to water, and thus the layout of the breaks in a paddock must be such as to permit of stock. having access to water at all times. Suggested types of breaks to allow of this, regardless of the position of the water trough, are shown on the next page.

The actual size of each day's break depends on the amount of growth in the paddock, the feed supply available, and the number of cows on the area. At the start of the season, when autumn-saved pasture is being utilised before the pasture growth starts to come away, cows are usually given about an hour's grazing, the! balance of. the feed being supplied as hay or silage. The size of the daily break is increased as the feed starts to get away, until finally the cows are grazing wholly on grass, with no supplements. It has been found under practical farming conditions that the average ryegrass-white clover-cocksfoot type of pasture that is commonly found on many of our dairy 

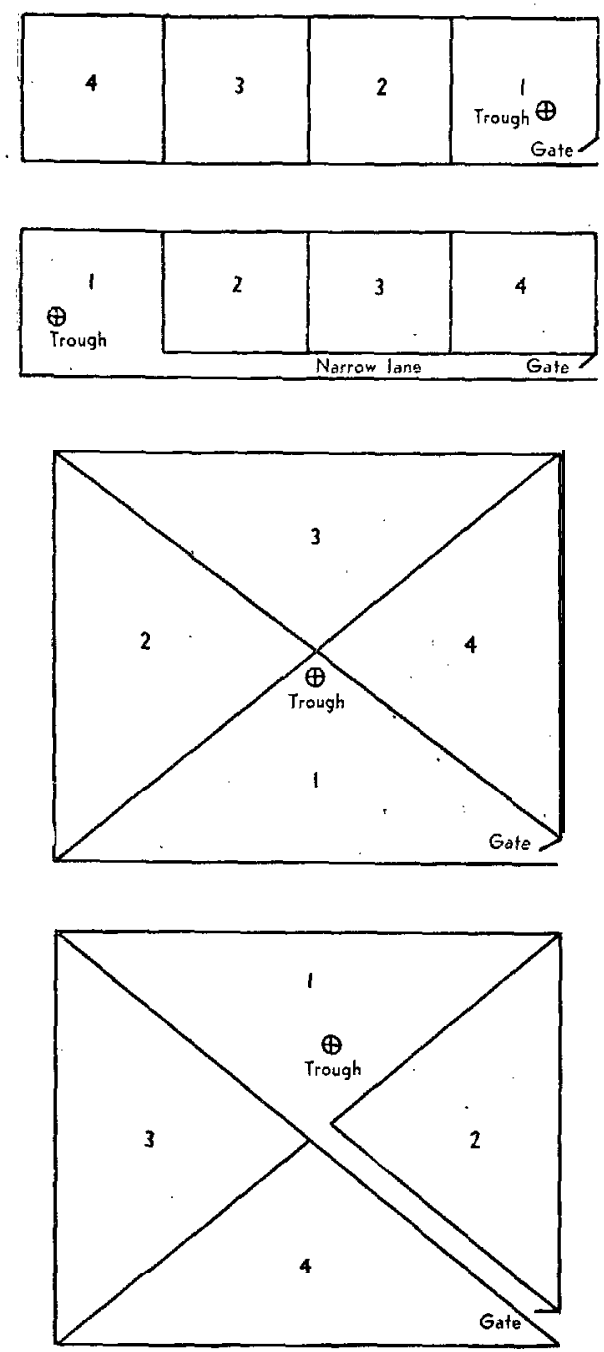

farms until Christmas should be divided into l-acre breaks for each day's grazing and \$-acre breaks for a night's grazing for every 100 COWS. A word of warning should be given at this stage to those farmers who have paspalum. It has been found that cows, if grazed on paspalum pastures with 7 to 8in. -of growth on them, will often start to drop rapidly in production, and it is suggested that such pastures should be grazed in the autumn when the growth is no more than 4 to 
5in. in height, that the area of the break be increased accordingly, and that topping be done With the mower when necessary.

Any farmer adopting this method of pasture management will find that he will have to rely on a little trial and error to determine the exact size of break to give, his cows each day. If the day's break is too small, cows will- hang around the gate about 3 p.m., while if the break is too big, feed will be wasted. In practice, it is suggested that it is preferable to have the break a shade too big rather than too small. As far -as the night's grazing is concerned, some farmers break feed their day paddocks and give the cows a full paddock at night. This is usually found on the larger holdings where there are set day and night paddocks. If this practice is unavoidable, it would be wise for the farmer to get another fence unit and break feed his night paddocks as well as the day ones. The ideal, however, is to have no night paddocks, but rather to graze every paddock both day and night. Some formers drop this break grazing once harvesting starts, claiming that they cannot afford the time to shift the fence each day. One way out of this difficulty is to break off sufficient areas to last a week, so that the farmer has only to shift the fence unit over to the new line each day, This is being done successfully on several farms.

Farmers adopting this system of grazing management will inevitably find that they will have more feed to cope with than ever before. Thus, more hay and silage can be saved and more cows milked, while existing stock should produce to capacity. It is suggested that a farmer adopting this system confine himself. in the first year to conserving the extra feed produced as silage or hay, and not try to milk too many extra cows. A valuable reserve of fodder can thus be built up, and his experiences during the season will give him a good indication of the carrying potential of his farm. During this time he can also be making preparations to milk extra cows in the following season, when the full benefits from rationed grazing can be reaped. As far as the management of the young stock under this system of rationed grazing is concerned, I would suggest that they be grazed about three paddocks ahead of the milking cows.

One factor limiting the effectiveness of break grazing is the ability of the herd to produce, and cases 
can be quoted of farmers adopting this system of management without getting substantial production increases, simply because their stock are not' good enough to take full advantage of the better-quality feed. This is but a further indication of the necessity for any pasture improvement programme being combined with one that ensures that the stock will be. good enough to take full advantage of such improved pastures.

What results are being obtained in practice from break grazing? The following are a few examples which should serve to illustrate the claim that this system, if brought into use wherever practicable, would play no small part in giving a marked increase in our dairy production.

The first example comes from a small Jersey stud near Tauranga. This property, situated on goodquality Katikati sandy loam, is 45 acres in area and subdivided into 17 paddocks. Before the introduction of rationed grazing it was producing $9000 \mathrm{lb}$ of butterfat yearly from 33 cows, and in addition carried 19 bulls, 13 2-year-old heifers, and 10 heifer calves. To carry this stock on the property the farmer used to purchase $\$ 300$ worth of hard feed yearly. In the 1949-50 season he introduced rationed grazing, giving the cows a fresh break daily. He started break grazing in May and carried it right on to the following January when there was such a drought that there was no grass' to break graze anyway. During the winter and early spring he found that a $3 \frac{1}{2}$-acre paddock of 6 to 8 -in. grass lasted 30 cows 15 days, when they were being given also hay and silage. In the season, after feeding out had finished, the same paddock lasted 33 cows for 3 full days and nights. During the season 'the area cut for supplementary feed increased 15 per cent., all as silage, and he spent only $£ 50$ on hard feed. His butterfat production increased by $1000 \mathrm{lb}$. butterfat. That autumn there was a 'bad drought, during which the extra silage cut proved to be invaluable. No bloat was experienced during the season, cows got in calf readily, and there were no hard quarters,

At the end of the season the farmer moved to a larger property near Whakatane, this time of 215 acres. Before this he completely disposed of his 33 pedigree cows and took over the new property as a going concern. He immediately introduced rationed 
grazing, and, with the same herd that had been on the property with the previous owner, had an increase in production of $70001 \mathrm{~b}$. of butterfat, and also increased the area cut for hay or silage by over 200 per cent., from 30 acres to 96 acres.

Another farmer at Katikati, on a property of 170' acres, was able to milk 10 extra cows and run 60 more head of young stock, increased his production by 50001 b. of butterfat, from 27,000 to 32,000 , and cut double the usual area for hay and silage. This year he will milk about 145 cows with ease. This farmer gave his cows a fresh break every 12 hours, and continued break feeding until the end of May. Cows were then wintered on about 40 acres, the rest of the farm being closed for winter-saved grass. He intends carrying on the system this coming season.

A farmer in the Te Puke district for years had been troubled with bloat every spring. His pastures were rather clovery, and every spring he had up to 60 cows bloated, losing many of them. In desperation he started using the electric fence and rationed grazing, and now has only the odd case of bloat each year. He allows his pastures to reach about $8 \mathrm{in}$. in height before putting the cows on them, and, in his own words, "It is a grand sight to see safe grass piling up ahead of the cows, and not to have the constant worry of bloat over my head."

My final example is a town supply farm in Auckland district, near Papatoetoe, on a good meadow soil. It is 117 acres in area, with 100 acres of good mixed pastures and 17 acres -of rock, gorse, and rough feed, and. milks 65 to 100 cows, depending on the time of the year. Since the introduction of rationed grazing in April 1950 the farmer has also been able to run 300 sheep, and his production has increased by $2000 \mathrm{lb}$. of. butterfat, from 22,303lb. to $24,490 \mathrm{lb}$. The area of grass cut for hay and silage has been increased from 45 acres to 80 acres. In the past no replacements have been raised on the property, but the farmer believes it will pay him to rear his own replacements now that he has so much extra feed. On this farm the cows are given a fresh break every 12 hours, and the dry cows follow up the milkers, going on to the stony ground in wet weather to avoid poaching the good pastures.

It must be realised that this system of break 
grazing is something that is fairly new, and that we have not yet got the answer to. all the problems associated with it.

Those farmers who are using it, however; consider that it is well worth a trial, and are satisfied that the results amply repay them for any extra work entailed, Not every dairy farm is suited to this method of management., but it could be used, at least in a modified form, on a majority of our dairy farms.

Farmers using this system of grazing management claim that this is the only way of utilising fully pasturage at its most productive stage, and that it has great possibilities of giving us that increase in dairy production so urgently needed.

\section{i DISCUSSION}

Q. With rationed grazing what harrowing is necessary? Also, does the speaker recommend two shifts every 24 hours, or one shift? At the time of spring flush grazing at 8in. stage, is there any difficulty in dealing with extra regrowth on the first break when the last break is being grazed off?

A. Most farmers harrow during early part of season. This is particularly necessary when the electric fence is being used in conjunction with feeding out. The amount of harrowing would depend largely on the fertility of the farm. There is better utilisation of feed if the fence is shifted every 12 hours, but the main object is to get farmers started on the system. The frequency of shifting is largely dependent on labour supply. If the paddock is no bigger than to permit of 5 days' grazing, there is no difficulty in coping with feed getting away on the first break when 'the last one is being grazed. This, however, can be a problem when paddocks are too large.

Q. What measures are taken to avoid taint-producing weeds, particularly cress, in new pastures?

A. The average size of new grass paddock is 5- to 9 acres. If put down properly in the autumn there is no serious invasion of weeds, particularly if short-rotation ryegrass is a dominant constituent of the seed mixture. Weed-infested pastures are best grazed by dry stock. Hormone weedkillers have given promising results in controlling cress. If the cows must be grazed on cress infested pasture, feed taints can be reduced by the use of controlled grazing which limits the grazing to particular times with relation to milking.

Q. With only one break daily is there a build-up in fertility with rationed grazing?

A. Yes; but shifting fences once daily is only a start. When a farmer has adopted the practice he can usually be induced to change the fence every 12 hours.

Q. Is there any transference of fertility over the paddock and what is the effect of sward composition? 
A. There is a more even distribution of droppings on the area. Providing pasture growth is not too long when grazed, indications are that there is no loss of clovers and no great increase in fog.

Q. What is the position regarding control of bloat by the electric fence?

A. In the case of a farmer near' Tauranga with a large area of special-purpose pasture, comprising short-rotation ryegrass, white clover, and red clover, trouble was experienced when the paddock was being grazed a second time round. The farmer overcame the trouble by using a day break for an hour and then turning the cows into a race for about an hour, when they were then put on to the break again. The fence is essential to avoid a selection of clovers over a large area. race?

Q. Does not this mean a transference of fertility to the

A. It is agreed that there would be some transference of fertility but-this is only over a short period of the year and in practice it is easier to shift cows than to shift a fence at frequent intervals during the day.

Q. It is not a negative approach to wait until cows are starting to bloat and then shift them ? If a cow becomes bloated, production falls. Better to try to maintain cows at highest production. What is the condition of dung when cows are being fed on and off the break in this fashion?

A.' It' is easier to operate this system on a farm with a limited labour supply. On the farm in question, when bloat started production fell greatly, but rose again to normal when the on-and-off system of grazing was adopted. Cows were not constipated in any way. It is a more practicable method for the average farmer under average farm labour conditions. 